\title{
AdAPTIVE PDE-BASEd MEDIAN FILTER FOR THE RESTORATION OF HIGH-DENSITY IMPULSE NOISE CORRUPTED IMAGES
}

\author{
Shanmugavadivu $\mathrm{P}^{1}$ and Eliahim Jeevaraj P $\mathrm{S}^{2}$ \\ Department of Computer Science and Applications, \\ Gandhigram Rural Institute - Deemed University, \\ Gandhigram - 624 302, Tamil Nadu, India \\ ${ }^{1}$ psvadivueyahoo.com, ${ }^{2}$ eliahimpsegmail.com
}

\begin{abstract}
This proposed Adaptive PDE-based Median Filter (APM Filter) is devised to suppress the high-density fixed-value impulse noise that degrades the quality of images. It is apparent from the quantitative measure - the PSNR values and the qualitative measure - the human visual perception that the noise suppression potential of APM filter is significantly higher. This filter broadly finds application in the areas, such as image/video documentation, medical imaging and remote sensing.
\end{abstract}

\section{KEYWORDS}

Adaptive Median Filter, Fixed-Value impulse noise, Highly corrupted image, PDE-based Median filter, Image restoration

\section{INTRODUCTION}

The grayscale digital image is an aggression of intensity values, represented in the form of twodimensional array. Normally, the digital images get corrupted by noise during acquisition and/or transmission, due to the influencing parameters of these processes such as faulty sensors, atmospheric turbulence [1], [2].

Noise is termed as any irrelevant data that obscures the authenticity of original data. Any noiseprone image has to necessarily undergo restoration process in order to make it suitable for subsequent higher order processing. Image restoration is an objective preprocessing technique that aims to estimate the original intensities of the corrupted pixels based on the mathematical model of noise, as noises are classified as impulse noise, gaussian noise, poisson noise, thermal noise, speckle noise, exponential noise, uniform noise etc., based on their pattern of distribution and characteristics [3]. This paper proposes an efficient adaptive non-linear filter to restore images corrupted with high-density fixed-value impulse noise. It is evident from the literature that, non-linear filters like median based filters outperform the linear filters like mean filters. 
International Journal of Advanced Information Technology (IJAIT) Vol. 1, No.6, December 2011

Besides this noise filtering ability, median filters tend to promise detail and edge preservation in the restores images [4], [5].

The proposed filter, Adaptive PDE-based Median Filter (APM Filter) processes any given noiseprone input image and produces a restored image as its output. The performance of APM filter is measured as PSNR values and Human Visual Perception. Further, the PSNR values of APM Filter are compared with its fourteen contemporary high-performing median based filters for further analysis. It is found that PSNR values of APM filter are higher than those contemporary filters for most of the noise probabilities and highly comparable for the remaining ones.

The fixed-value impulse noise model is described in section 2 and the mathematical background of PDE is given in section 3. The principle of APM filter is detailed in section 4. The results and discussion is presented in section 5 and the conclusions in section 6 .

\section{NOISE MODEL OF FIXED-VALUE IMPUlSE NOISE}

Impulse noise is categorized into fixed-value impulse noise and random-value impulse noise. This APM filter is designed to restore the images corrupted with fixed-value impulse noise, which assumes either minimum or maximum intensity value of the image and the percentage of noise distribution is evenly divided by those two intensity values. Random value impulse noise arbitrarily assumes any value between the minimum and maximum intensity value of the image [6], [7].

The fixed-value impulse noise corrupted image, $\mathrm{X}_{\mathrm{i}, \mathrm{j}}$ can be expressed as a composite component of corrupted and uncorrupted pixels as:

$$
X_{i, j}^{\prime}=\left\{\begin{array}{l}
N_{i, j} \text { with probability } \mathrm{p} \\
\mathrm{U}_{\mathrm{i}, \mathrm{j}} \text { with probability }(1-\mathrm{p})
\end{array}\right.
$$

where $\mathrm{N}_{\mathrm{i}, \mathrm{j}}$ and $\mathrm{U}_{\mathrm{i}, \mathrm{j}}$ denotes the corrupted and original pixels [8].

\section{Partial Differential Equations}

In physics, if a network region (mesh) is partitioned into small grids, then the central point of each grid is computed using Laplace Equation (Eqn.2) as[9]:

$$
\frac{\partial^{2} u}{\partial x^{2}}+\frac{\partial^{2} u}{\partial y^{2}}=0
$$

In the above equation, when the derivatives are replaced by their difference approximations (Eqn.3), it is known as Diagonal 5-point formula which is pictorially represented in Figure 1 and finds wider applications in image processing.

$$
\mathrm{M}_{\mathrm{i}, \mathrm{j}}=\frac{1}{4}\left[\mathrm{M}_{\mathrm{i}-1, \mathrm{j}-1}+\mathrm{M}_{\mathrm{i}+1, \mathrm{j}-1}+\mathrm{M}_{\mathrm{i}+1, \mathrm{j}-1}+\mathrm{M}_{\mathrm{i}+1, \mathrm{j}+1}\right]
$$


International Journal of Advanced Information Technology (IJAIT) Vol. 1, No.6, December 2011

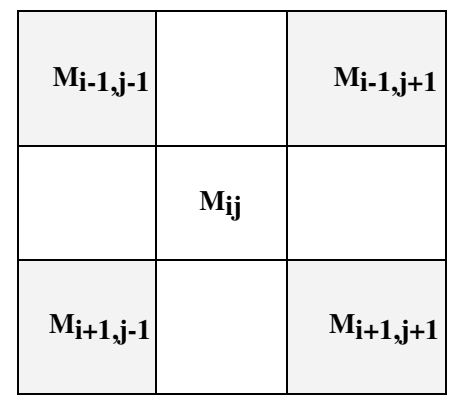

Figure 1. Neighborhood points of PDE

In APM filter for the purpose of denoising, the diagonal 5-point formula is modified in such a way that the central pixel $\mathrm{M}_{\mathrm{ij}}$ is excluded and the median is computed using the remaining neighbouring pixels [10]-[12].

\section{APM FILTER}

The proposed APM filter performs denoising in two stages namely noise detection and noise correction.

\subsection{Noise Detection}

In a grayscale image of dynamic intensity range [0-255], fixed-value impulse noise corrupted pixels assume either 0 or 255. The APM filter partitions the corrupted input image into subimages of size $\mathrm{n} \times \mathrm{n}$, checks if the central pixel is corrupted or not and every corrupted pixel is treated in the noise correction phase.

\subsection{Noise Correction}

In each subimage, if the central pixel is corrupted, then its original intensity value is estimated using the principle of neighbourhood processing. For this purpose, the neighbourhood pixels of every subimage with a corrupted pixel at the central position $\left(\mathrm{M}_{\mathrm{ij}}\right)$ are classified into corrupted pixels $\left(\mathrm{C}_{\mathrm{P}}\right)$ and uncorrupted pixels $\left(\mathrm{U}_{\mathrm{P}}\right)$. Then, the median of those neighbourhood uncorrupted pixels is computed as $\mathrm{U}_{\mathrm{MED}}$ and are respectively replaced in the output image $\mathrm{Y}^{\prime}$. Further, the median of diagonal pixels of $\mathrm{W}$ in $\mathrm{Y}^{\prime}$ is computed as $\mathrm{D}_{\mathrm{MED}}$ and is used to replace respective pixel in the output image $\mathrm{Y}^{\prime}$. This process is uniformly repeated for the entire image. 
International Journal of Advanced Information Technology (IJAIT) Vol. 1, No.6, December 2011

\subsection{Algorithm of APM Filter}

Input: The corrupted image $\mathrm{X}^{\prime}$ and a copy of $\mathrm{X}^{\prime}$ as $\mathrm{Y}^{\prime}$

Output: The restored image $\mathrm{Y}^{\prime}$

Step 1: Read the corrupted image $\mathrm{X}^{\prime}$ and copy $\mathrm{X}^{\prime}$ into '.

Step 2: Divide $\mathrm{X}^{\prime}$ and $\mathrm{Y}^{\prime}$ into subimages in the order of overlapping sliding window $\mathrm{W}$ of size $n \times n$.

Repeat steps 3 to 5, for each W:

Step 3: Check whether the central pixel $\mathrm{M}_{\mathrm{ij}}$ is corrupted or not

Step 4: If $\mathrm{M}_{\mathrm{ij}}$ is uncorrupted, goto Step 3.

Step 5: If $\mathrm{M}_{\mathrm{ij}}$ is corrupted,

i. Group the uncorrupted pixels of $\mathrm{W}$ as $\mathrm{U}_{\mathrm{P}}$ and the corrupted ones as $\mathrm{C}_{\mathrm{p}}$.

ii. Compute the median of $U_{P}$ pixels of $W$ as $U_{M E D}$

$$
\mathrm{U}_{\mathrm{MED}} \leftarrow \operatorname{Median}\left(\mathrm{U}_{\mathrm{P}}\right)
$$

iii. Replace the corresponding $C_{P}$ pixels of $\mathrm{W}$ in $\mathrm{Y}^{\prime}$ by $\mathrm{U}_{\mathrm{MED}}$.

iv. Compute the median of diagonal pixels of $\mathrm{Y}^{\prime}$ in $\mathrm{W}$.

$$
D_{M E D} \leftarrow \operatorname{Median}\left[M_{i-1, j-1}, M_{i+1, j-1}, M_{i+1, j-1}, M_{i+1, j+1}\right] .
$$

v. $\quad \mathrm{M}_{\mathrm{ij}} \leftarrow \mathrm{D}_{\mathrm{MED}}$

Step 6: Update the respective value of $\mathrm{M}_{\mathrm{ij}}$ in $\mathrm{Y}^{\prime}$.

Step 7: Stop 
International Journal of Advanced Information Technology (IJAIT) Vol. 1, No.6, December 2011

\subsection{Flowchart of APM Filter}

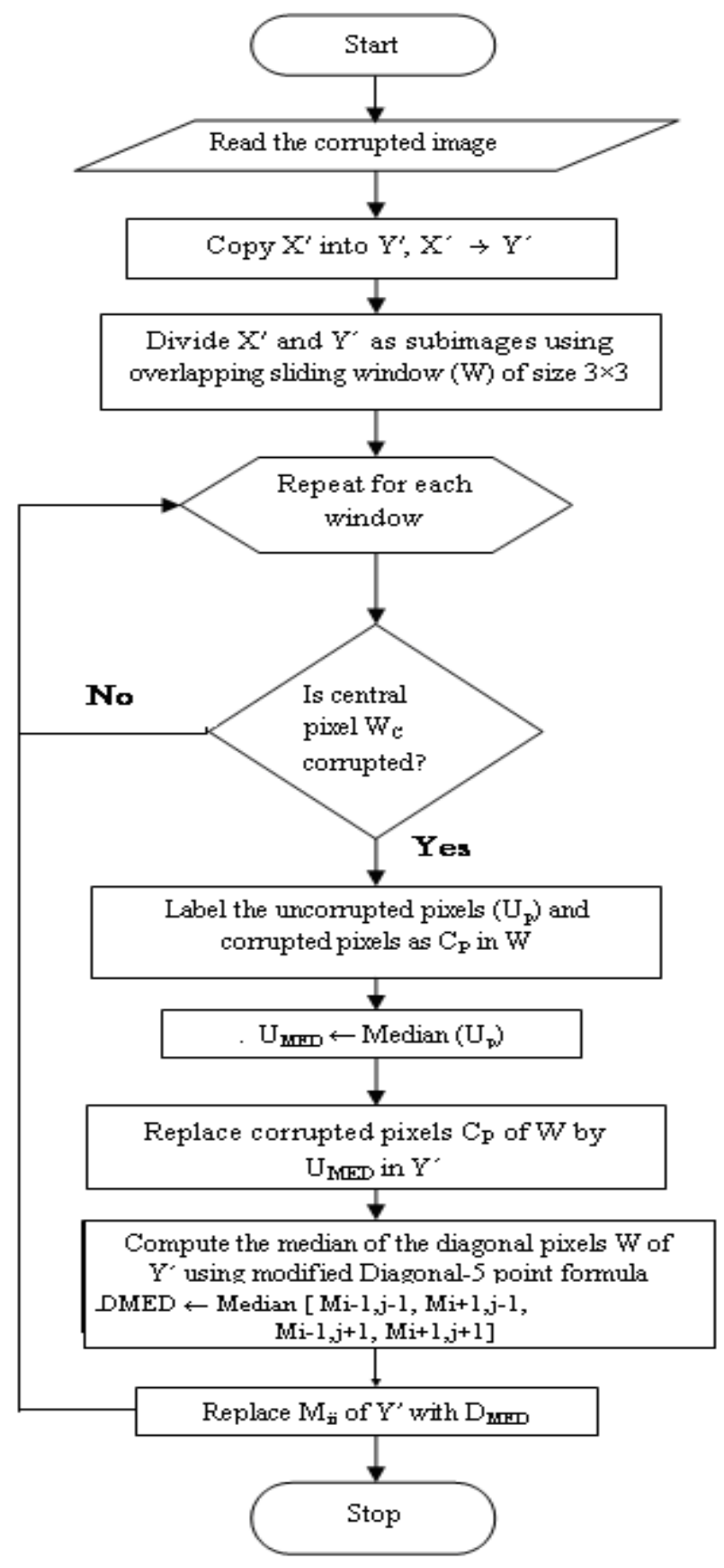

Figure 2. Flowchart of APM Filter 
International Journal of Advanced Information Technology (IJAIT) Vol. 1, No.6, December 2011

\section{RESULTS AND DISCUSSION}

The proposed filter is developed using MatLab 6.5. The standard images lena and mandrill are chosen as the test images. The images are corrupted with noise probabilities of $10 \%-90 \%$ and the window size is chosen as $3 \times 3$. The performance of the proposed filter is measured in terms of PSNR and human visual perception.

The performance of the APM filter is comparatively analyzed with a few median based filters like Standard Median Filter (SM), Center Weighted Median Filter (CWM), Progressive Switching Median Filter (PSM), Iterative Median Filter (IMF), Signal Dependent Rank Order Median Filter (SDROM), Two-state Recursive Signal Dependent Rank Order Median Filter (SDROMR), NonRecursive Adaptive-Center Weighted Median Filter (ACWM), Recursive Adaptive-Center Weighted Median Filter (ACWMR), Russo's Fuzzy Filter (RUSSO), Zhang's Filter (ZHANG), Sun and Neuvo's Switching Based Filter (SUN), Impulse Rejecting Filter (IRF) and Tri-State Median Filter (TSM) and Modified PDE Adaptive Two-Stage Median Filter(MPATS) [13],[14].

The recorded PSNR values of lena and mandrill are furnished in Table I and Table II. It is observed that except the noise probabilities of $10 \%$ and 20\%, APM filter produces the highest PSNR values though for these noises, the PSNR value of APM filter is highly comparable with those of its contemporary filters.

It is further clear from Table II that APM filter has given the highest PSNR values than all of its contemporary filters. Additionally, the visual perception of the restored images of lena and mandrill for the noise probabilities of 50\%, 60\% and 70\% depicted in Figure 4, substantiates the denoising capability of APM filter.

Table I. Comparison of PSNR values for Lena image

\begin{tabular}{|l|c|c|c|c|c|c|c|c|c|}
\hline \multirow{2}{*}{ Method } & \multicolumn{7}{|c|}{ Noise Density (\%) } \\
\cline { 2 - 10 } & $\mathbf{1}$ & $\mathbf{2 0}$ & $\mathbf{3}$ & $\mathbf{4}$ & $\mathbf{5}$ & $\mathbf{6}$ & $\mathbf{7}$ & $\mathbf{8}$ & $\mathbf{9}$ \\
\hline Corrupted & 15.5 & 12.4 & 10.7 & 9.4 & 8.5 & 7.7 & 7.0 & 6.4 & 5.9 \\
\hline SM & 28.7 & 26.4 & 22.6 & 18.3 & 15.0 & 12.2 & 9.8 & 8.1 & 6.5 \\
\hline CWM & 29.7 & 24.1 & 19.5 & 15.7 & 13.0 & 10.8 & 8.9 & 7.6 & 6.3 \\
\hline PSM & 30.7 & 28.7 & 26.9 & 23.7 & 20.0 & 15.2 & 11.1 & 8.3 & 6.4 \\
\hline IMF & 27.2 & 26.7 & 26.1 & 25.1 & 23.9 & 21.2 & 16.6 & 12.1 & 8.0 \\
\hline SDROM & 30.3 & 26.7 & 22.0 & 17.6 & 14.4 & 11.7 & 9.4 & 7.8 & 6.4 \\
\hline SDROMR & 30.5 & 28.5 & 25.7 & 23.5 & 20.7 & 17.8 & 14.2 & 10.6 & 6.9 \\
\hline ACWM & 30.9 & 27.2 & 22.4 & 18.1 & 14.8 & 12.1 & 9.7 & 8.1 & 6.5 \\
\hline ACWMR & 31.4 & 28.8 & 25.8 & 23.3 & 20.8 & 18.1 & 15.0 & 11.8 & 8.1 \\
\hline RUSSO & 31.0 & 27.6 & 24.9 & 22.7 & 20.3 & 17.6 & 14.7 & 11.7 & 8.6 \\
\hline ZHANG & 32.8 & 28.2 & 23.3 & 18.6 & 15.3 & 12.5 & 10.0 & 8.3 & 6.7 \\
\hline SUN & 31.0 & 27.5 & 23.0 & 18.4 & 15.0 & 12.2 & 9.8 & 8.1 & 6.5 \\
\hline IRF & 30.2 & 27.0 & 22.5 & 18.2 & 14.9 & 12.2 & 9.7 & 8.1 & 6.5 \\
\hline TSM & 30.3 & 24.4 & 19.6 & 15.5 & 12.7 & 10.4 & 8.4 & 7.1 & 6.0 \\
\hline MPATS & 32.3 & 28.9 & 26.9 & 24.8 & 23.5 & 21.6 & 19.6 & 17.9 & 15.0 \\
\hline $\begin{array}{l}\text { APM } \\
\text { (Proposed Filter) }\end{array}$ & 31.6 & 29.0 & 27.1 & 25.3 & 24.0 & 22.7 & 21.3 & 19.8 & \multirow{2}{*}{17.4} \\
\hline
\end{tabular}


International Journal of Advanced Information Technology (IJAIT) Vol. 1, No.6, December 2011

Table II. Comparison of PSNR values for Mandrill image

\begin{tabular}{|l|c|c|c|c|c|c|c|c|c|}
\hline \multirow{2}{*}{ Method } & \multicolumn{9}{|c|}{ Noise Density } \\
\cline { 2 - 11 } & $\mathbf{1 0}$ & $\mathbf{2 0}$ & $\mathbf{3 0}$ & $\mathbf{4 0}$ & $\mathbf{5 0}$ & $\mathbf{6 0}$ & $\mathbf{7 0}$ & $\mathbf{8 0}$ & $\mathbf{9 0}$ \\
\hline Corrupted & 15.7 & 12.6 & 10.9 & 9.6 & 8.6 & 7.9 & 7.2 & 6.6 & 6.1 \\
\hline SM & 23.8 & 23.0 & 20.7 & 17.7 & 14.7 & 12.3 & 10.9 & 8.3 & 6.8 \\
\hline CWM & 25.5 & 22.7 & 18.9 & 15.6 & 12.9 & 10.9 & 9.1 & 7.7 & 6.6 \\
\hline PSM & 27.8 & 26.4 & 25.0 & 22.9 & 19.5 & 15.3 & 11.0 & 8.9 & 6.5 \\
\hline IMF & 23.0 & 22.8 & 22.6 & 22.3 & 21.5 & 20.0 & 16.0 & 12.0 & 8.3 \\
\hline SDROM & 26.0 & 24.0 & 20.8 & 17.4 & 14.3 & 11.8 & 9.6 & 7.9 & 6.6 \\
\hline SDROMR & 25.8 & 24.6 & 23.2 & 21.8 & 19.7 & 17.6 & 14.2 & 10.8 & 7.1 \\
\hline ACWM & 27.1 & 24.8 & 21.4 & 17.9 & 14.8 & 12.3 & 9.9 & 8.2 & 6.8 \\
\hline ACWMR & 27.5 & 25.7 & 23.9 & 22.3 & 20.2 & 18.2 & 15.4 & 12.4 & 8.8 \\
\hline RUSSO & 29.5 & 26.7 & 24.3 & 22.4 & 20.2 & 17.7 & 15.0 & 11.9 & 8.9 \\
\hline ZHANG & 28.8 & 26.1 & 22.1 & 18.5 & 15.2 & 12.7 & 10.2 & 8.4 & 6.9 \\
\hline SUN & 26.1 & 24.4 & 21.3 & 18.0 & 14.8 & 12.3 & 9.9 & 8.2 & 6.7 \\
\hline IRF & 25.8 & 24.1 & 21.2 & 17.8 & 14.7 & 12.3 & 9.9 & 8.2 & 6.8 \\
\hline TSM & 25.4 & 22.9 & 18.9 & 15.4 & 12.6 & 10.5 & 8.6 & 7.2 & 6.2 \\
\hline MPATS & 29.6 & 27.0 & 24.8 & 23.8 & 22.4 & 21.1 & 19.9 & 18.2 & 17.1 \\
\hline $\begin{array}{l}\text { APM } \\
\text { (Proposed Filter) }\end{array}$ & 29.6 & 26.9 & 24.8 & 24.0 & 22.6 & 21.7 & 20.7 & 19.5 & 18.0 \\
\hline
\end{tabular}

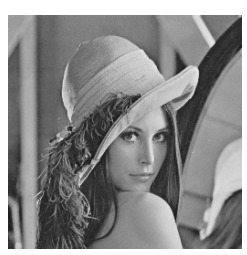

(a)

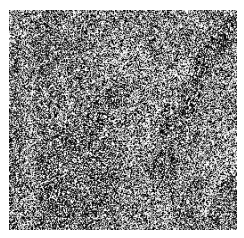

(f)

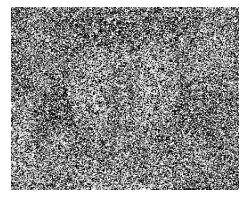

(k)

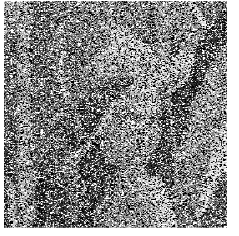

(b)

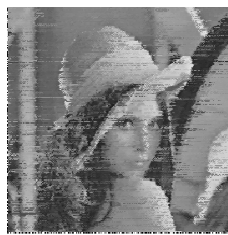

(g)

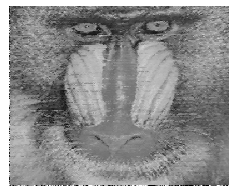

(1)

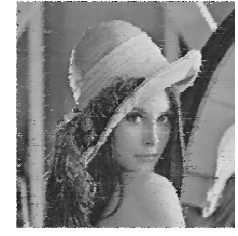

(c)

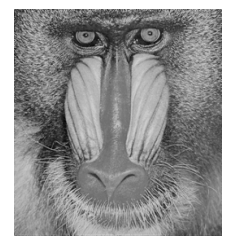

(h)

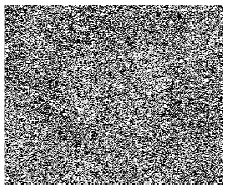

(m)

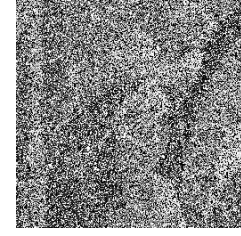

(d)

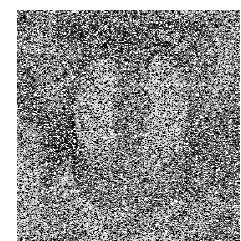

(i)

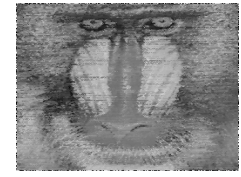

(n)

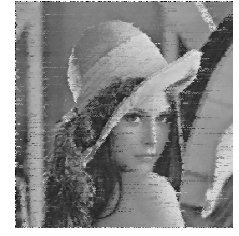

(e)

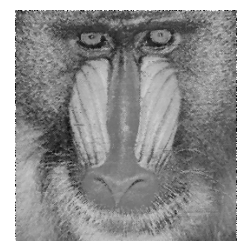

(j)

Figure 3. (a) Original image of Lena (b) Lena image with $50 \%$ noise; (c) Filtered Image of (b); (d) Lena image with 60\% noise; (e) Filtered Image of (d); (f) Lena Image with 70\% noise; (g) Filtered Image of (f); (h) Original Image of Mandrill (i) Mandrill Image with 50\% noise; (j) Filtered Image of (i); (k) Mandrill Image with 60\% noise; (l) Filtered Image of (k); (m) Mandrill Image with $70 \%$ noise; (n) Filtered Image of (m); 
International Journal of Advanced Information Technology (IJAIT) Vol. 1, No.6, December 2011

\section{Conclusion}

The APM filter promises a high degree of restoration of digital images, degraded by fixed-value impulse noise of density up to $90 \%$. Hence, it is found to be very effective in denoising the highly corrupted images. Further, the proposed filter also ensures better preservation of the details and edges of the input images, which is confirmed quantitatively in terms of PSNR values and qualitatively as visual perception.

\section{ACKNOWLEDGEMENT}

Authors wish to place on record the financial assistance received in the form of a Major Research Project from UGC, New Delhi, India and the authorities of the Gandhigram Rural Institute Deemed University for their support and encouragement.

\section{REFERENCES}

1. Gonzalez. R.C, Woods R.E, Digital Image Processing, Third Edition, Pearson Prentice Hall, India, 2009.

2. Somasundaram $\mathrm{K}$ and Shanmugavadivu $\mathrm{P}$, Adaptive Iterative Order Statistics Filters, Journal of ICGST - GVIP, Vol. 09, pp.23-32, 2009.

3. Behrooz Ghandeharian, Hadi Sadoghi Yazdi and Faranak Homayouni, Modified Adaptive Center Weighted Median Filter for Suppressing Impulsive Noise in Images, International Journal of Research and Reviews in Applied Sciences, Vol. 01, No. 03, 2009.

4. Satpathy S.K, Panda S, Nagwanshi K.K and Ardill C, Image Restoration in Non-Linear Domain using MDB approach, IJICE, Vol. 06, No. 01, 2010.

5. Somasundaram K and Shanmugavadivu P, Impulsive Noise Detection by Second Order Differential Image and Noise Removal using Nearest Nieghbourhood Filter, International Journal of Electronics and Communications, pp.472-477, 2007.

6. Md. Mansoor Roomi S, Lakshmi IM and Abhai Kumar V, A Recursive Gaussian Weighted Filter for Impulse Noise Removal, Journal of ICGST - GVIP, Vol. 06, No. 03, pp.33-37, 2006.

7. Windya P.S, Fast Impulse Noise Removal, IEEE Trans. on Image Processing, Vol.10, No.01, pp.173-179, 2001.

8. Shanmugavadivu P and Eliahim Jeevaraj P S, Selective 8-Neighbourhood based Medan Filter for Images Corrupted with High Density Fixed-Value Impulse Noise, $3^{\text {rd }}$ IIST, 2011.

9. Grewal B.S, Higher Engineering Mathematics, Second Edition, Khanna Publishers, New Delhi, pp.1129-1130, 2007.

10. Yu Li You, Kaveh M, Fourth order PDE for noise removal, IEEE Trans. on Image Processing, Vol. 09, No.10, pp.1723-1730, 2000.

11. Shanmugavadivu P and Eliahim Jeevaraj P S, Fixed - Value Impulse Noise Suppression for Images using PDE based Adaptive Two -Stage Median Filter, ICCCET-11 (IEEE Explore), pp.290-295, 2011.

12. Bertozzi A.L and Greer J.B, Travelling Wave Solutions of Fourth Order PDEs for Image Processing, SIAM, Journal of Mathematical Analysis, Vol.36, No.01, pp.36-68, 2004.

13. Besdok E and Emin Yuskel M, Impulsive Noise Suppression for Images with Jarque - Bera Teat based Median Filter, International Journal of Electronics and Communications, Vol. 59, pp.105110, 2005.

14. Shanmugavadivu $\mathrm{P}$ and Eliahim Jeevaraj P S, Modified Partial Differential Equations based Adaptive Two-Stage Median Filter for Images Corrupted with High Density Fixed-Value Impulse Noise, CCSEIT 2011,CCIS 204, Springer-Verlag, pp. 376 -383 
International Journal of Advanced Information Technology (IJAIT) Vol. 1, No.6, December 2011

\section{Authors}

P. Shanmugavadivu received Ph.D., in Image Restoration from the Department of Computer Science and Applications, Gandhigram Rural Institute - Deemed University, Gandhigram, India, in 2008 and is working as Associate Professor in the same department. Her research areas are image restoration, image enhancement and image segmentation.

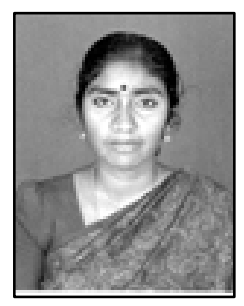

Eliahim Jeevaraj P S is pursuing Ph.D., at Department of Computer Science and Applications, Gandhigram Rural Institute - Deemed University, India. He completed his MCA degree in Bishop Heber College, Tiruchirappalli. His research interests are image restoration and image enhancement.

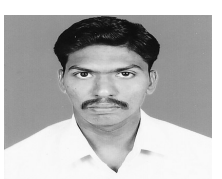

